\title{
Circularly Polarized Antenna Array Technique for MIMO Application
}

\author{
Bhaghyashree Sharma \\ Research Scholar \\ Geetanjali Instt. of Tech. Studies
}

\author{
Rajeev Mathur \\ Research Scholar \\ SGVU, Jaipur
}

\begin{abstract}
This paper presents the design of a $2.77 \mathrm{GHz}$ MIMO antenna with two rectangular patches loaded by two split ring resonator (SRR) as the antenna elements. Each antenna element has area of $56 \times 25 \mathrm{~mm}^{2}$. A compact and low correlation coefficient antenna system covering bandwidth $178 \mathrm{MHz}$ for wireless communication standards is proposed.

First, a linearly polarized rectangular patch antenna is discussed. In order to increases the circular polarization; the patch structure is further modified into split ring structure. An array of such split ring is then constructed to increases the directivity, axial ratio, gain and efficiency. The antenna is fabricated on a FR4 substrate.

The performance of the proposed antenna design is analyzed and the results are compared with the simulations using IE3D tool. Through the analysis of mutual coupling and correlation between each pairs of antenna ports, it is shown that the antenna achieves good polarization and directivity diversity. A high diversity gain is therefore being achieved. The performance results exhibited by the proposed antenna make it extremely useful for the future generation of wireless broadband communication system.
\end{abstract}

\section{General Terms}

Antenna design, simulation, fabrication, VNA testing, comparisons of results.

\section{Keywords}

Rectangular patch, rectangular patch loaded with SRR, antenna array, MIMO application, wireless communication.

\section{INTRODUCTION}

In wireless communication systems, due to the limited physical size of mobile devices, the application of multiple antennas is proposed. Nowadays, multiple-input multipleoutput (MIMO) systems have become one of the hottest research topics due to the magnificent enhancement brought by multiple antenna techniques.

In wireless communication widely used antenna is rectangular patch antenna although it has some limitations like low impedance bandwidth, gain, radiation efficiency and directivity. In order to improve radiation efficiency and directional gain some modifications are required in rectangular patch.

Square split ring resonator structure is loaded on rectangular patch and array of such structure is proposed which increase coverage, reduce the correlation coefficient, increase efficiency, increase axial ratio and antenna design becomes circularly polarized. $[1,2,4,5]$

\section{ANTENNA DESIGN}

The resonating frequency, dielectric constant, loss tangent and substrate height are taken as $2.77 \mathrm{GHz}, 4.4,0.002$ and $1.588 \mathrm{~mm}$. For substrate FR4 material is used as it is cheap and easily available. The effective length and width of the rectangular patch are calculated as $56 \mathrm{~mm}$ and $25 \mathrm{~mm}$ respectively as shown in fig 1. [6]

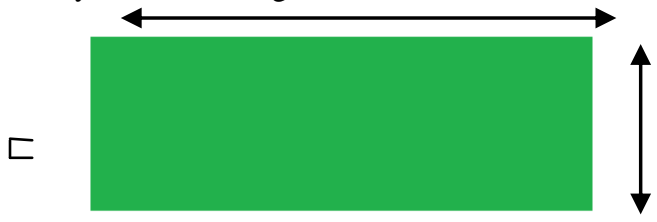

Fig 1:- Rectangular patch

First, the rectangular patch is formed and simulated than it is loaded with two square split ring resonators as shown in fig 2 and investigated.

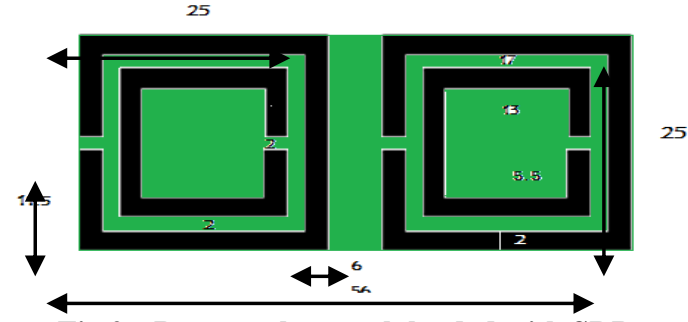

Fig 2:- Rectangular patch loaded with SRR

Antenna array of two elements is made in which both the elements of the array are separated by $57 \mathrm{~mm}(\lambda / 2)$ as shown in fig 3 .

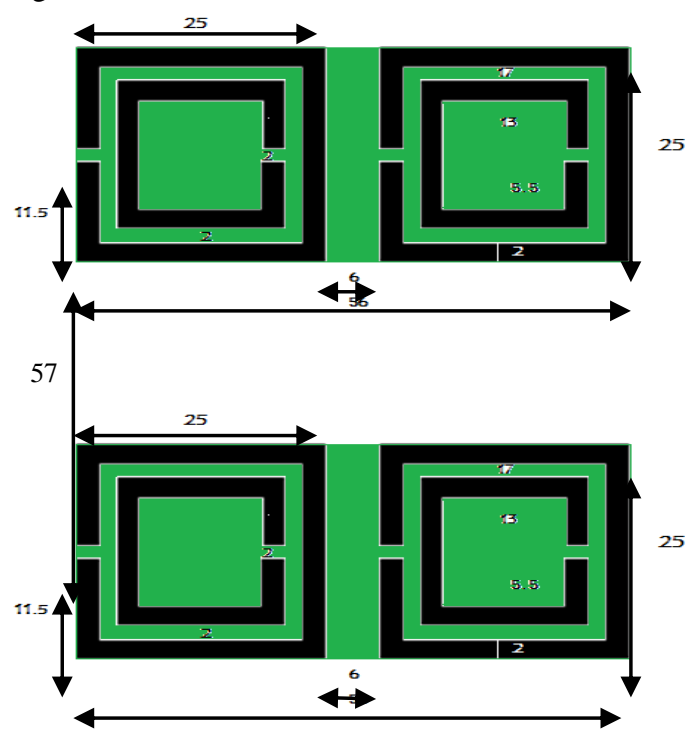

Fig 3:- Antenna array 
These three designs of antenna are go through simulation. Over all structure of designed antenna is shown in the fig 4 in which rectangular patch loaded with two square split ring resonators is shown.

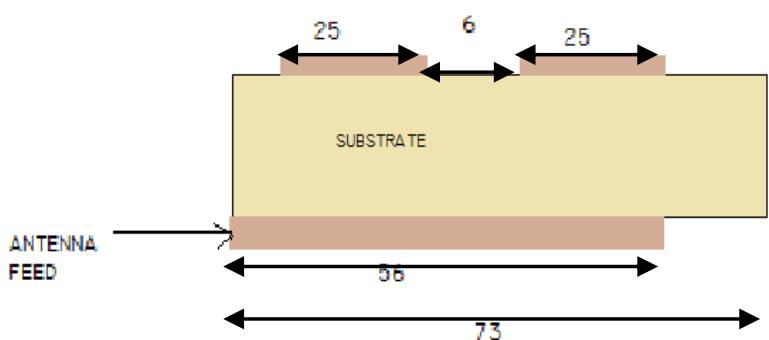

Fig 4:- Overall structure of designed antenna

\section{SIMULATION RESULTS}

The three designed discussed in antenna design section is simulated in IE3D.

The simulation results of first design at resonating frequency gives return loss-19db, gain 6db, efficiency $70 \%$ and axial ratio 0 which shows that antenna is linearly polarized.

The simulation results of second design at resonating frequency gives return loss- $16 \mathrm{db}$, gain $2.7 \mathrm{db}$, axial ratio between 0 and 1 which shows that antenna is elliptically polarized.

The simulation results of third design at resonating frequency gives return loss $-18 \mathrm{db}$, gain $7 \mathrm{db}$, efficiency $100 \%$, axial ratio more than 1 which shows that antenna design is circularly polarized.

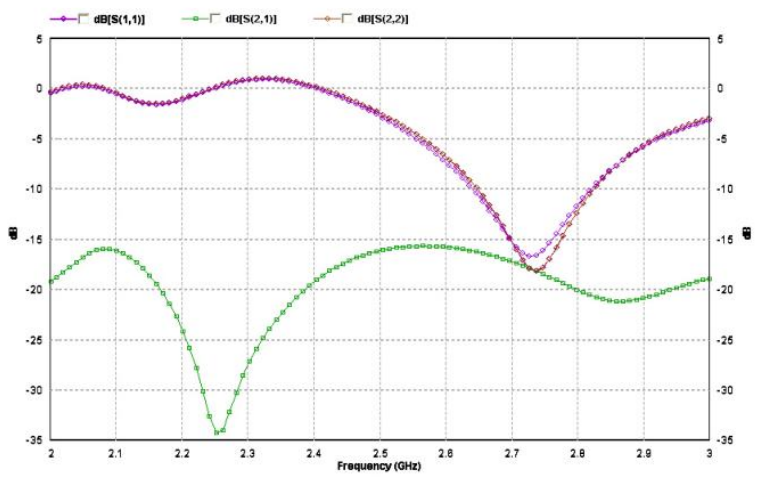

Fig 5:- Comparison of return loss between rectangular patch loaded with SRR and antenna array

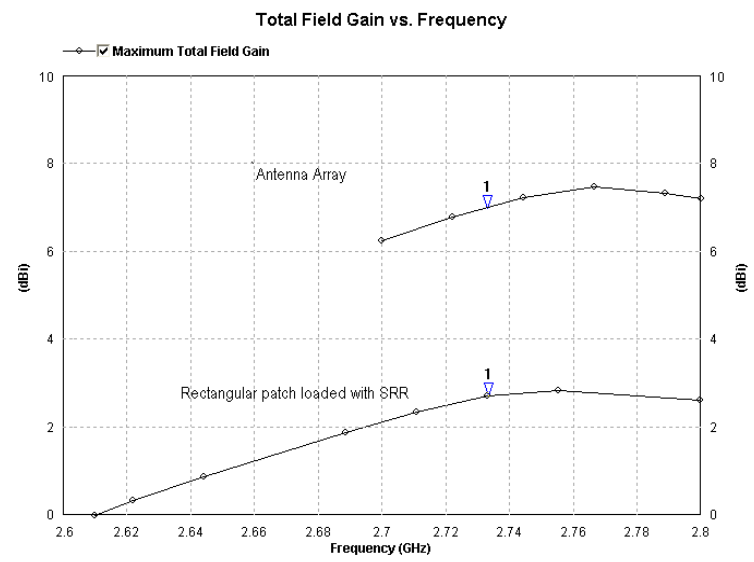

Fig 6:- Comparison of field gain between rectangular patch loaded with SRR and antenna array

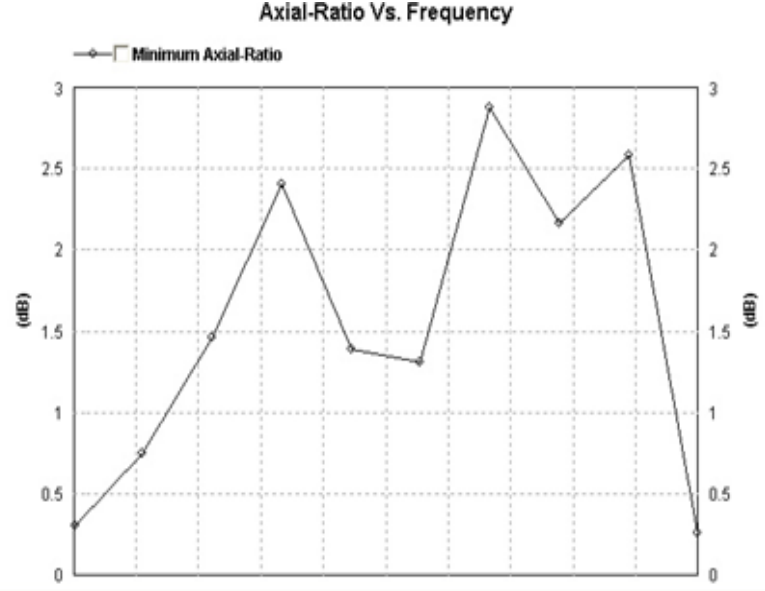

Fig 7:- Axial ratio versus frequency for antenna array

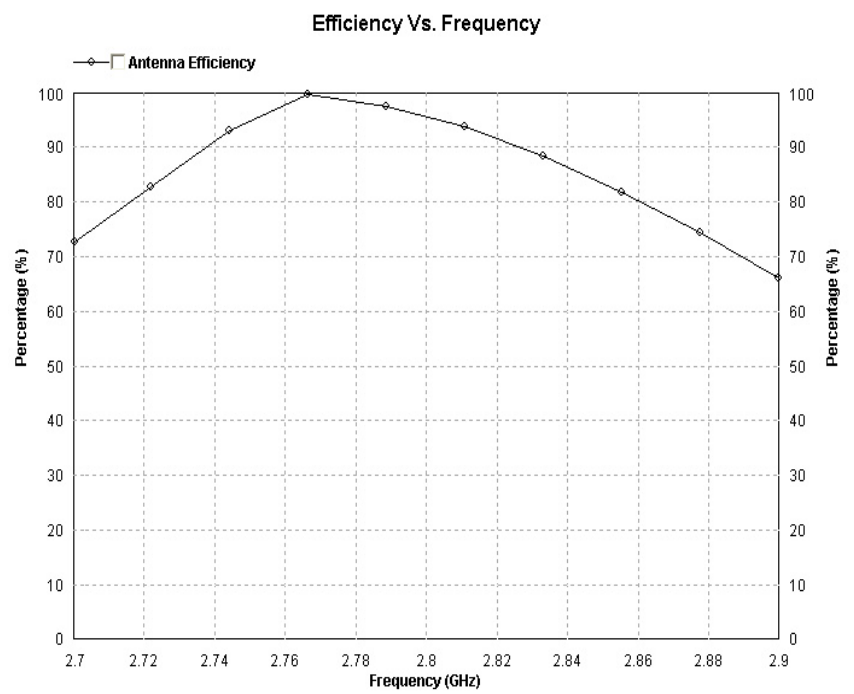

Fig 8;- Efficiency versus frequency for antenna array

The correlation coefficient at resonating frequency is 0.0012 . It is computed in MATLAB. [3]

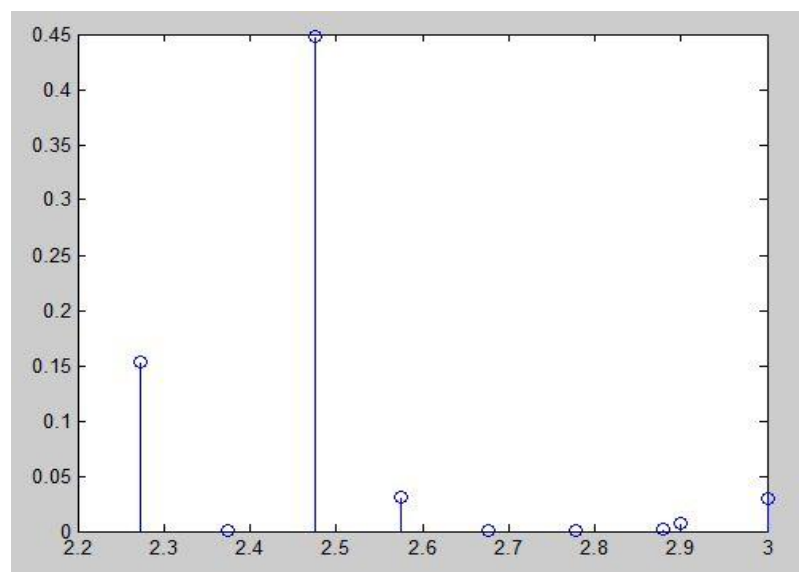

Fig 9:- Correlation coefficient versus frequency 


\section{FABRICATION PROCESS}

Fabrication of any antenna contain some general steps like draw a design in AUTOCAD, take a print of it on glossy sheet, double sided PCB printing, PCB cutting, etching, removal of black print, soldering of SMA connector.

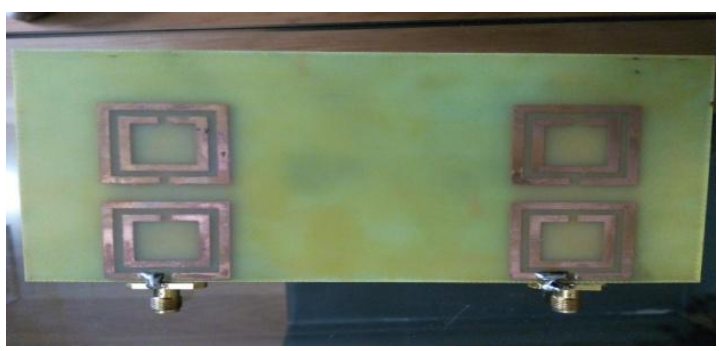

Fig 10:- Fabricated proposed antenna design

Fabricated proposed antenna design is go through VNA testing. Second and third design is tested by VNA.

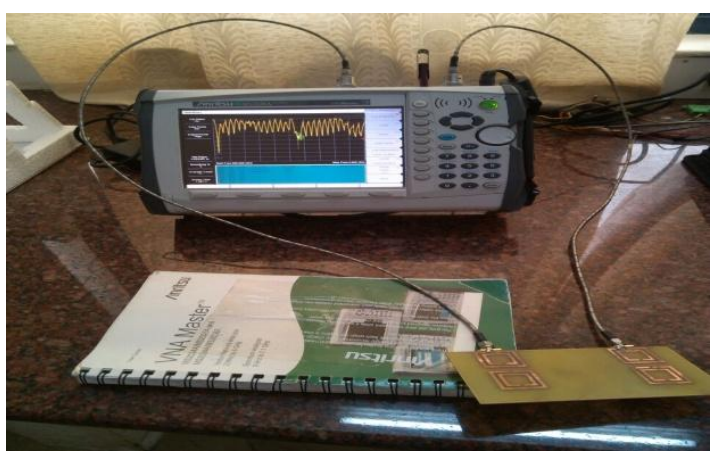

Fig 11:- VNA testing of proposed antenna design

\section{COMPARISONS OF RESULTS AND CONCLUSION \& FUTURE SCOPE}

Comparison of simulation results and VNA testing results are shown below in form of a table.

Table 1:- Comparison table

\begin{tabular}{|l|l|l|l|l|}
\hline S. NO. & Design & Parameters & $\begin{array}{l}\text { Simulation } \\
\text { result }\end{array}$ & $\begin{array}{l}\text { VNA } \\
\text { testing } \\
\text { result }\end{array}$ \\
\hline 1. & Second & $\begin{array}{l}\text { Return } \\
\text { loss }\end{array}$ & $-16 \mathrm{db}$ & $-23 \mathrm{db}$ \\
\hline 2. & Third & $\begin{array}{l}\text { Return } \\
\text { loss }\end{array}$ & $-18 \mathrm{db}$ & $-32 \mathrm{db}$ \\
\hline
\end{tabular}

It is concluded from the above analysis that antenna array is operated at $2.77 \mathrm{GHz}$. By the analysis of simulation results of design second and third it can say that gain is enhanced by $4.33 \mathrm{db}$ from $2.77 \mathrm{db}$ to $7 \mathrm{db}$, return loss by $2 \mathrm{db}$ from $-16 \mathrm{db}$ to $18 \mathrm{db}$, axial ratio is increases from less than 1 to more than 1 which make the design circularly polarized.

To enhance compactness and portability of the design, reduction in size is suggested. For this purpose research which will do in future is focused on finding new methods to further reducing the size of antenna array. This design can be extended in such a manner so that it can be applicable for the other application related to MIMO system like WLAN, WMAN, RFID, 4G, Mesh networks and digital home. MIMO has good coverage with good speed and high reliability so that it can easily connect with various devices like cabled video devices, computer networking devices, broadband connections, phone lines, music, storage devices etc. hence it can enables in the application of digital home.

\section{ACKNOWLEDGMENTS}

I would like to express my thanks to my guide, Mr. Rajeev Mathur, Head of Department of Electronics \& Communication, GITS, Udaipur

\section{REFERENCES}

[1] E. Stavrou, O. Litschke, R. Baggen, C. Oikonomopoulos "Dual-Beam Antenna for MIMO WiFi Base Stations," the $8^{\text {th }}$ European conference on antenna and propagation (EuCAP 2014), vol. No. 978-88-907018-4-9/14/\$31.00@) 2014 IEEE, pp. $1869-1871$.

[2] S. Zhang, K. Zhao, B. Zhu, Z. Ying, and S. He "MIMO reference antenna with controllable correlation and total efficiencies" progress in electromagnetic research, pier 145, 115-121, 2014 DOI : 10.2528/pier 14010507

[3] W. Li, W. Lin, and G. Yang "A compact MIMO antenna system design with low correlation from $1710 \mathrm{MHz}$ to $2690 \mathrm{MHz}$ " progress in electromagnetic research, pier 144, 59-65, 2014 doi : 10.2528/pier 13111305

[4] Mathur, R.; Joshi, S., "A novel multiple element patch antenna for wireless MIMO beamforming and WiMAX applications," International Conference on Emerging Trends in Networks and Computer Communications (ETNCC), 2011, vol., no., pp. 110-114, 22-24 April 2011 doi: 10.1109/ETNCC.2011.5958497

[5] Haili Zhang, Zhihong Wang, Jiawei Yu, and Jia Huang "A compact MIMO antenna for wireless communication" IEEE antenna and propagation magazine, vol. 50, no. 8, december 2008

[6] Antenna theory by C.A. Balanis. 